\title{
Fire Safety System Design Using Risk Assessment Models: Developments in Australia
}

\author{
V. R. BECK \\ Department of Civil and Building Engineering \\ F.I.T.-Victoria University of Technology \\ P.O. Box 64, Footscray, Victoria 3011, Australia
}

\begin{abstract}
Australia has achieved a very good fire safety record. However, concern has been expressed at the possible excessive costs which may be incurred in achieving this fire safety record, and the need to identify cost-effective design solutions. In response, pressures have developed to introduce a performance-based approach to enable more flexible and rational engineering methods to be applied for fire safety and protection system design. A brief description is given of a performance-based approach to design using risk assessment models. Given also is an outline of the previous research, and the current research which is either in progress, or which is required to be undertaken, to produce reliable estimates of risk-to-life safety. Results from the risk assessment model are used to identify cost-effective fire safety system designs for buildings.
\end{abstract}

KEYWORDS: Design, Fire Engineering, Performance Criteria, Risk Assessment

\section{INTRODUCTION}

Absolute protection of life and property from fire in the built environment is unattainable and, even if attainable, prohibitively expensive. However, too little expenditure on fire safety could result in levels of life loss that would be unacceptable to the community. Between these extremes will exist a set of cost-effective solutions, in which it is feasible to minimise the total cost associated with fire, consistent with achieving levels of life safety which are acceptable to the community.

The severe consequences of fire in buildings have caused communities to control the design and use of buildings through laws and regulations. The good fire safety record which has been achieved in Australia may be attributed, in part, to current building regulations. However, the regulations are both prescriptive and restrictive in their application. Further, the evolutionary nature of the development of building regulations 
may result in excessive conservatism, limited application of fire engineering technology, and with indications that such codes are not optimal in the interest of the society they serve. Consequently, concern has been expressed at the possible excessive costs which may be incurred in achieving our fire safety record, and the need to identify cost-effective design solutions.

In response to this environment, pressures have developed to introduce performance-based approaches to enable more flexible and rational engineering methods to be applied to fire safety and protection design; such methods are being developed in Australia. Emphasis has been given to researching techniques which can be used to assess the risk to life of the occupants by considering the interaction between fire growth and spread, human behaviour, and the performance of engineering subsystems installed in buildings. The broad objective for this research in Australia is the development of systematic methods to rationally design cost-effective fire safety and property protection systems in buildings, based on an assessment the risks and costs involved. Research has been in progress for some 10 years now to develop risk assessment models to estimate both the risks to life safety and the economic consequences of the effects of fire in buildings.

During 1991 the Commonwealth Government has made several grant allocations totalling some $\$ 1 \mathrm{M}$ to the Victoria University of Technology, (in some cases in association with the Australian Centre for Building Fire Safety and Risk Engineering refer to the Acknowledgement section ), to support the development of risk assessment modelling for the identification of cost-effective fire safety system designs.

\section{COST-EFFECTIVE FIRE SAFETY SYSTEM DESIGN}

It has long been recognised that in order to reliably manage the effects of various hazards, including the effects of fire in buildings, it is not appropriate to rely solely on a single component or subsystem. Rather, authorities and the community require a level of redundancy by specifying that a number of components or subsystems be incorporated in a design to ensure there is an adequate level of hazard management. However, it is the very issue of specifying potentially excessive levels of protection, as well as levels of redundancy, that has resulted in concern about the excessive cost of providing fire safety and protection in buildings. Consensus is developing that building regulations in Australia prescribe excessive levels of redundancy in either the number or the extent of components or subsystems required to provide fire safety and protection in buildings.

In Australia, there is a growing body of opinion that to systematically determine appropriate and cost-effective fire safety system designs, it is necessary to undertake risk assessment modelling. A fire safety system represents a particular combination of fire safety subsystems; for example passive and active subsystems. Deterministic models are appropriate to use when either analysing or specifying a particular fire safety and protection component or subsystem, assuming that the particular component or subsystem is working perfectly, in isolation, and under defined conditions. However, it is also recognised that fire safety and protection components and subsystems do not work perfectly, and that there is always a finite chance of failure of such components and subsystems when subjected to fire conditions. Accordingly, it is appropriate to have combinations of fire safety subsystems to provide levels of redundancy and ensure adequate levels of safety and protection. However, in order to analyse the performance of the fire safety system it is necessary to have a framework which quantifies the overall effect of different combinations of levels of performance of the fire safety subsystems. Risk assessment models provide a rational framework to define the probability of events when components or fire safety subsystems either operate successfully or fail, to define the consequences of such events occurring, and to combine 
the results of such assessments into various quantified performance parameters. Accordingly, risk assessment models enable cost-effective fire safety system designs to be identified which contain various levels of redundancy.

\section{RISK ASSESSMENT MODELLING - OVERVIEW}

The precise level of protection that is afforded to occupants and property against the effects of fire is difficult to quantify because of the complexity of and interaction between fire growth and spread, fire detection and warning, fire suppression and protection strategies and human behaviour. To represent these interactions, risk assessment models (RAM) have been developed using an event-tree formulation (Beck $[1,2,3])$ to assess the performance of fire safety systems in buildings.

For cost-effective fire safety system designs, consideration should be given to the level of safety afforded to occupants of buildings, and to the costs associated with the provision of such safety. When considering alternative designs, such an approach enables designers to select the most appropriate cost-effective solution. Accordingly, the risk assessment models that have been developed characterise the performance of a building design in terms of two parameters, namely:

(a) expected risk-to-life (ERL), and

(b) fire-cost expectation (FCE).

The expected risk-to-life (ERL) parameter is a measure of the risk of fatalities from fire to the occupants of a building over the expected life of the building. The ERL parameter can include, if so desired, the component of risk of fatalities to fire brigade personnel. The fire-cost expectation (FCE) parameter incorporates various direct capital and maintenance costs and fire losses (and is defined subsequently).

To identify alternative designs which are considered equivalent to, and more cost-effective than, designs conforming with current regulatory provisions, the decision criterion adopted was (Beck[3]): "For an alternative design to be considered acceptable the expected risk-to-life value shall be equal to, or less than, the risk-to-life value of a building conforming with the building regulations (code), and the fire-cost expectation for the alternative design shall be less than the value for the conforming building".

With such a comparative approach it is not necessary to directly compare estimated risk-to-life values, derived from a risk assessment model, with an acceptable risk level derived from independent sources. This approach also avoids difficulties associated with assigning monetary value to human life. The expected risk-to-life values for designs conforming with current regulatory requirements provides both an estimate of current levels of risk to life safety, and a convenient reference, or benchmark, to compare the performance of other designs. These risk levels are assumed to be acceptable to the community. However, reduced or higher levels of risk may be justified or sought for a variety of reasons. For example, it is unclear whether the current regulatory requirements imply a consistency of risk levels. It is expected that a wide dispersion of risk levels will exist, and that once these levels are known it may be appropriate to rationalise these levels and, in some cases, define new target levels of risk.

It should be noted that the RAMs have been developed to identify cost-effective design solutions for building fire safety systems. It is not appropriate to use RAM as a predictive tool to model an actual fire scenario since the performance parameters derived using the RAM are expected values which represent the combined effects of different fire scenarios and different levels of performance of the fire safety subsystems. The current RAM uses three specified design fires (smouldering fires, non-flashover fires and fires which flashover) to characterise the full spectrum of fires 
expected in reality. While the use of three design fires represents a restriction, realistic modelling approaches are, or will be, adopted to estimate the various effects of fire growth and spread in buildings. Accordingly, it is expected that the resultant estimated risk-to-life values obtained from the model will provide a reasonable (but somewhat conservative) estimate of the historical risk-to-life values derived from a range of similar buildings.

\section{PREVIOUS RISK ASSESSMENT RESEARCH}

The research into risk assessment modelling in Australia was commenced by the author in 1979. While the research work was generic in its focus, the initial application of this work was office buildings; four papers and one $\mathrm{PhD}$ thesis describing this work were published $[1,2,3,4,5]$. In 1987 , the author undertook a four month sabbatical period at the National Research Council of Canada (NRCC). Subsequent research collaboration undertaken between the author and the NRCC has resulted in three papers of joint authorship [6,7,8].

While the research undertaken during this phase has laid the foundation for the subsequent research which has been undertaken, the RAM contains a number of deficiencies. For example, the state-transition models used to characterise fire growth in the enclosure of fire origin resulted in inadequate attention being given to the modelling of time effects. This was particularly the case when estimating the time of fire growth and spread, and the times of occurrence of detection, warning and response of occupants to the presence of fire. The submodel used to estimate the probability of smoke spread was overly simplistic, and the submodel used to estimate the probability of flame spread was restrictive. In addition, the smoke spread and flame spread submodels did not include time effects. For example, in the case of the flame spread submodel probability values were determined at those times which are at least equal to the duration of fire exposure in the building.

In 1989 the author was appointed as Visiting Professorial Fellow at the Warren Centre for Advanced Engineering, the University of Sydney, to lead a project on Fire Safety and Engineering. The objective of the Warren Centre is to undertake technological transfer of advanced engineering and to promote excellence in engineering in Australia. The Fire Safety and Engineering Project [9] was undertaken during 1989 in conjunction with some 70 Project Fellows. During the Warren Centre project, demonstration risk assessment models (DRAM) were developed to investigate the potential applicability of risk assessment models. The DRAM represented a departure from the previously developed RAM in that greater emphasis was given to the calculation of the times of occurrence of flashover, fire spread from the enclosure of fire origin and detection of fire. This was achieved, in part, by the introduction of design fires at the suggestion of Quintere [10]. However, because of resource constraints during the project, it was not possible to develop reliable submodels to estimate times and probabilities applicable to both smoke spread and flame spread.

At the conclusion of the Warren Centre project consensus was reached on the need for fire safety design to be treated as an engineering responsibility, and the need to provide an alternative approach to prescriptive regulatory control. Further, it was concluded that risk assessment models should be the basis for introducing rational engineering techniques to identify cost-effective fire safety system designs for buildings. It was also recognised that both the risk assessment model and input data should be further developed to improve their reliability before they could be used for design purposes.

A sequel to the Warren Centre project is the development of the first draft of a National Building Fire Safety Systems Code (NBFSSC). The NBFSSC project was 
commissioned by the Building Regulation Review Task Force which was established in Australia at a Special Premiers' Conference in 1989. The objective of the NBFSSC is to provide flexible and technologically advanced procedures (based on risk assessment modelling) for the achievement of cost-effective building designs which conform to the fire safety levels implicit in the building regulations. However, to enable the NBFSSC to be published as an Australian Standard, and for it to be routinely applied for design purposes, considerable development is required. A brief description of the NBFSSC project is given by Beck [11].

\section{CURRENT RISK ASSESSMENT RESEARCH}

\section{General}

Current research into risk assessment modelling, which represents a progressive development of the research previously conducted, has been stimulated by the discussions undertaken during the Warren Centre project and the National Building Fire Safety Systems Code project (refer to previous section). The risk assessment model (RAM) has been restructured into a separate risk assessment submodel, together with six related submodels as shown in Figure 1. Previously, risk assessment was incorporated directly into parts of other submodels, and this made it difficult to improve the reliability of each of the submodels. The current structure of the RAM will facilitate the ready updating of the submodels to reflect advances in technology. The submodels are being developed cognisant of the technology which exists, and the availability of data to estimate the required parameters for the submodels. It is recognised that in some cases good quality data does not exist; in such cases use will be made of expert opinion to develop the required data.

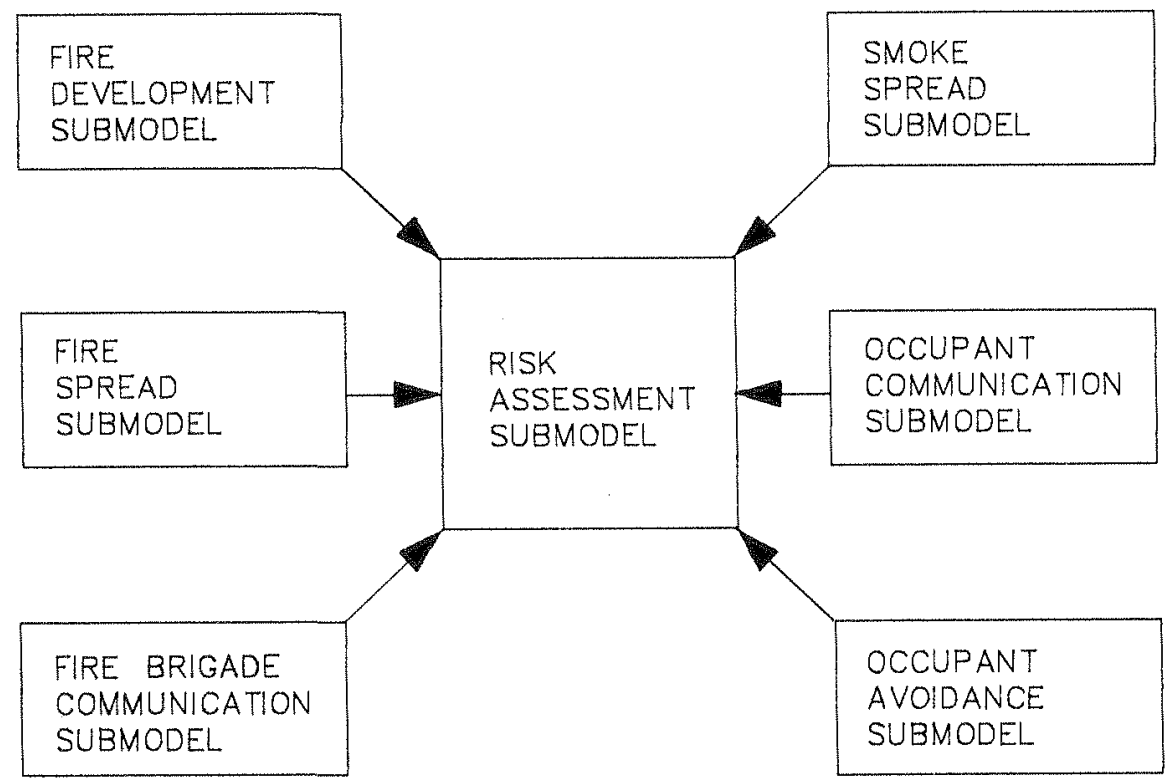


Given below is a description of the purpose of each submodel, a brief outline of the current modelling approach, and the research that is either underway or that is required to be undertaken to improve the reliability of the parameters which are calculated using the submodels.

\section{Risk Assessment Submodel}

The Risk Assessment Submodel is used to calculate the building fire safety system performance parameters; namely the expected risk-to-life parameter and the fire-cost expectation parameter. The expected risk-to-life (ERL) performance parameter is defined as follows:

ERL =
the Design Life of the Building
$\begin{aligned} & \text { Building } \times \quad \text { Design } \\ & \text { Population }\end{aligned}$ Life of Building

Further details on the ERL parameter are given in Beck $[3,4]$.

The expected life loss during the design life of the building, ELLD, is broadly defined as follows:

\begin{tabular}{|c|c|c|c|c|c|}
\hline ELLD & $\begin{aligned} &= \text { Probability that } \\
& \text { Untenable Conditions } \\
& \text { Occur due to Particular } \\
& \text { Fire Scenarios }\end{aligned}$ & $X$ & $\begin{array}{l}\text { Probability that } \\
\text { People can be } \\
\text { Exposed to } \\
\text { Untenable } \\
\text { Conditions }\end{array}$ & $\mathrm{X}$ & $\begin{array}{l}\text { Number of } \\
\text { People Exposed } \\
\text { to Untenable } \\
\text { Conditions }\end{array}$ \\
\hline
\end{tabular}

The fire-cost expectation (FCE) performance parameter comprises the following direct costs and losses:

(a) Capital cost for the fire safety system.

b) Maintenance and inspection costs for the fire safety system.

(c) Expected monetary losses from fire.

The present worth sum of these components is defined as the FCE. Further details on calculation of the FCE parameter are given in Beck [3,4].

Essentially, the Risk Assessment Submodel is used to define various fire scenarios, to determine the probability of occurrence of untenable conditions for each of these scenarios, and using estimates of the number of people exposed to untenable conditions (as determined from the Occupant Avoidance Submodel), to calculate the expected life loss during the design life of the building, and hence the ERL parameter. In the Risk Assessment Submodel various fire scenarios are defined using the concept of design fires (refer to the Fire Development Submodel). In addition, the performance of the various fire safety subsystems included in the design are also defined; fire safety subsystems attempt to ameliorate the effects of fire and facilitate the avoidance by occupants of the effects of fire. The risk assessment model (RAM) has the capability of considering a wide variety of fire safety subsystems; for example, refer to Table 2 of Beck and Yung [8].

The Risk Assessment Submodel is based on the use of an event tree, state-transition formulation to define the expected number of deaths. Typical examples of these state-transition models have been published previously; refer to Figures 5,6 and 7 of Beck [1].

The previous and current risk assessment models are based on the assumption that with the occurrence of defined critical event, no further occupant evacuation may be 
undertaken. Currently, the critical event is defined to be the occurrence of untenable conditions in the stairs. These models are also based on the use of discrete values of probability (applicable at infinite time) to define the occurrence of untenable conditions. Research is in progress to define the occurrence of untenable conditions as a time-dependent probability function for each enclosure in the building, dependent on the location of the enclosure of fire origin.

\section{Fire Development Submodel}

The Fire Development Submodel is used to calculate the time of occurrence of particular events in the enclosure of fire origin; namely the time of occurrence of:

(a) automatic detection of the presence of fire,

(b) auditory, olfactory and visual cues (associated with the fire) which are detectable by building occupants,

(c) smoke obscuration which will hinder the way finding ability of the building occupants, and

(d) untenable conditions - that is lethal conditions for occupants resulting from exposure to toxic gases and thermal effects.

Various criteria can be used to define the occurrence of each of the above events. For example, during the Warren Centre project, particular criteria were selected for the above events (refer Table 3.3, Part 4, Book 1, Warren Centre Report [9]). The times of occurrence of such events, calculated using the Fire Development Submodel, are used as input to other submodels; namely:

(a) Time of Detection - used in each of the other submodels

(b) Time of Smoke Obscuration - used in the Occupant Avoidance Submodel

(c) Time of Untenable Conditions - used in the Occupant Avoidance Submodel.

To facilitate the computations, it was decided to adopt the concept of design fires. Three design fires were selected to represent the full spectrum of fires expected in buildings; namely:

(a) Smouldering fires

(b) Non-flashover fires

(c) Flashover fires.

The proportion of occurrence of each of these three design fires are determined from historical fire statistics. The basic proportions of each of the three design fires are modified to reflect the performance of various extinguishing facilities (including sprinklers, hydrants, hose reels and portable extinguishers), provided such facilities are included in the building fire safety design. The specified design fires are representative of severe fires (for example, 95 percentile values), in each of the three categories of fires. The design fires are specified in term of their output - heat release rate, smoke production rate and toxic gas production rate. For simplicity, toxic gases are assumed to be represented entirely by carbon monoxide and carbon dioxide.

The determination of the quantities of combustion products and the times of occurrence of particular events was accomplished in the Warren Centre project using mathematical models as follows:

(a) Smouldering Fires - a model based on the work of Quintiere et al [12].

(b) Non-flashover and Flashover Fires - the "FAST" model was used (Jones [13]).

There are a number of difficulties associated with the use of the "FAST" model. For example, the "FAST" model requires as input the specification of the design fire in terms of the time dependent burning rate and the generation rates of carbon monoxide and other toxic gases. Such input information, however, is not 
readily available. In addition, the "FAST" model takes considerable computer time to run, especially for those cases where the door is closed.

As part of the collaborative research effort on risk assessment modelling, the National Research Council of Canada have developed a simplified compartment fire growth model using a one-zone approach. The model by Takeda and Yung [14] produces results which compare favourably with the "FAST" model. The model predicts more conservative, but realistic, carbon monoxide and carbon dioxide concentrations than the "FAST" model. Furthermore, the model runs on PCs with a CPU time much faster than the "FAST" model. This is an important consideration when developing a risk assessment model which can be used on a routine basis for design purposes.

Research is also required to develop models which can reliably predict the development of fires in large enclosures that are typical of open-plan office layouts. Subsequent research may permit the replacement of the deterministic design fire approach with distributions for event times together with a state-transition probabilistic formulation of the type described by Roux and Berlin [15].

\section{Smoke Spread Submodel}

The Smoke Spread Submodel is used to calculate the performance of smoke and toxic products subsystems. Examples of such subsystems include either barriers, or barriers combined with pressure differential or air velocity control mechanisms. The purpose of such subsystems is to limit the spread of smoke and toxic products to and within enclosures, other than the enclosure of fire origin. In particular, the Smoke Spread Submodel is used to calculate; for each design fire the:

(a) Time and probability of successful operation of the subsystem.

(b) Time and probability of failure of the subsystem.

(c) Time and probability of arrival of untenable conditions due to smoke and toxic products when the subsystem is either non existent, or is not working successfully.

Results developed from the Smoke Spread Submodel are used directly in the Risk Assessment Submodel.

Successful operation of a smoke and toxic products subsystem is defined to occur when the subsystem both operates, and is successful in controlling the spread of smoke and toxic products for specified design fires. The time of successful operation may be deduced from an analysis of the time of automatic detector operation (as determined by the Fire Development Submodel), and subsystem. hardware response time. The probability of successful operation of the subsystem is currently assigned on the basis of expert opinion. However, research is required to develop models which can estimate the probability of subsystem performance based on an analysis of both the reliability of the subsystem, and the ability of the performance delivered by the subsystem to control the spread of smoke and toxic products under specified fire conditions.

The estimation of smoke movement in a building is not a simple matter due to complexities involved. A number of models have been developed to predict smoke movement and smoke concentration in buildings. Most of these models are deterministic in nature. However, for the purposes of the Risk Assessment Submodel, it is necessary to predict the probability of arrival of untenable conditions. As part of the collaborative research effort on risk assessment modelling, the National Research Council of Canada has developed a simplified 
smoke movement model. The model of Hadjisophocleous and Yung [16] is used to calculate the probability of spread at a critical time. The model is used to estimate concentration of toxic gases (carbon monoxide and carbon dioxide) on floors above the fire floor by considering the mass flow rates throughout a building. The calculation of probabilities is based on the assumption that the risk to occupants is proportional to the concentration to which occupants are exposed. The concentrations are calculated up to a critical time which is defined as that time at which occupants of the building cannot escape through the stairs safely, due to the presence of smoke. The smoke concentration conditions in the stair are calculated. These conditions are assessed to be lethal when the carbon monoxide and carbon dioxide dosage to a person on the top floor, trying to escape through the stairs, is equal or above a defined critical dosage.

Further research is required to remove the restriction of terminating the calculations at a "critical time", and to determine the probabilities of arrival of untenable conditions, due to the spread of smoke and toxic products, as a function of time in all enclosures in buildings.

\section{Fire Spread Submodel}

The Fire Spread Submodel is used to calculate the performance of fire spread subsystems. Examples of such subsystems include either barriers (including closures in such barriers), or barriers combined with active systems (such as automatic closures or extinguishing facilities).

In the following discussion emphasis will be placed on the performance of barriers. The purpose of Fire Spread Subsystems is to limit the spread of fire to and within enclosures. In particular, the Fire Spread Submodel is used to calculate, for appropriate design fires, the:

(a) Time and probability of successful operation of the system or component - if the subsystem comprises active components.

(b) Time and probability of failure of the subsystem or component.

(c) Time and probability of arrival of untenable conditions, due to fire spread. Results developed from the Fire Spread Submodel are used directly in the Risk Assessment Submodel for the calculation of both the Expected Risk-to-Life and Fire-Cost Expectation performance parameters.

Previously developed risk assessment models have employed models to calculate the probability of failure of individual barriers when subjected to post-flashover fires (Beck[3]). The probability of failure of individual barriers is used to assemble a reliability network which is then used to calculate the probability of fire spread from one enclosure to any other enclosure in the building using a model developed by Dusing et al [17].

The models that were used to calculate the probability of failure of barriers for fire spread considered the constituent probability of failure for each of the following limit states: structural adequacy, insulation, integrity and openings (such as doors, windows and inadvertent construction openings). The probability of failure models for barriers are described by Beck [2,3]. These models are used to calculate an upper bound estimate of probability of failure, applicable to those durations which are at least equal to the duration of fire exposure in an enclosure. Accordingly, the calculated probabilities of fire spread from one enclosure to another (Beck [3]) also represent an upper bound estimate of probability of fire spread, applicable to those durations which are at least equal to the duration of fire exposure in a building. 
The probability of failure calculations for a barrier are based on the consideration that both the fire severity and the resistance of the barrier (for a particular limit state) are random variables. The specified design fire (used in the Fire Development Submodel) is simply an upper bound value for the distribution of fires applicable to the specified design fire under consideration.

Further research is underway to remove the restriction of calculating a single value, upper bound estimate for both the probability of failure of a barrier and the probability of flame spread between any two enclosures in a building. This research will lead to the calculation of the probabilities of arrival of untenable conditions, due to fire spread, as a function of time in all enclosures in a building. For these objectives to be achieved, improved and more comprehensive probability models must be developed for both barriers and fire spread networks.

\section{Occupant Communication and Response Submodel}

The Occupant Communication and Response Submodel is used to calculate the performance of occupant response to the existence of fire cues which form part of the occupant communication and response subsystem. A fire may be detected by occupants using any one, or a combination, of the following fire cues:

(a) direct occupant detection of a fire through visual, auditory or olfactory means,

(b) indirect occupant detection of a fire following receipt of a warning by other occupants who have already detected the presence of fire, or

(c) automatic detection and alarm.

The Occupant Communication Submodel is used to calculate, for each design fire, both the time and probability performance of occupant response to the existence of the fire cues. Results developed from the Submodel are used both in the Occupant Avoidance Submodel (time of response) and the Risk Assessment Submodel (probability of response).

It is recognised that upon the receipt of a fire cue, occupants are unlikely to respond immediately by taking some action which may include occupant avoidance, or attempt at extinguishing the fire, and/or warning others. Rather, occupants will undertake investigative actions, or await the arrival of further cues before deciding to respond to the presence of fire. Accordingly, the time of response is defined as follows:

$\begin{aligned} & \text { Time of Occupant } \\ & \text { Response }\end{aligned}=\begin{aligned} & \text { Time of Arrival } \\ & \text { of a Cue }\end{aligned}+\begin{aligned} & \begin{array}{l}\text { Delay Period for } \\ \text { Investigation }\end{array} \\ & \text {. }\end{aligned}$

The Time of Arrival of a Cue is calculated using the Fire Development Submodel. The Delay Period for Investigation is contingent upon both the type of cue and the nature of the occupants.

The Probability of Response is defined as follows:
Probability of
Response
$=\quad$ Probability
of Cue
$\begin{array}{ll}X & \text { Probability of } \\ \text { Response Given Cue }\end{array}$

Currently both variables, namely the delay period for investigation and the probability of response, are based upon expert opinion. Further research is required to quantify both these variables on the basis of recording occupant response under both simulated and actual emergency conditions. 
The Fire Brigade Communication and Response Submodel is used to calculate the performance of the fire brigade action. The performance of the fire brigade depends upon the fire brigade communication and response management subsystem. The management subsystem includes those factors which affect the fire brigade arrival time, set-up time and extinguishment performance. The Submodel is used to calculate the following parameters:

(a) Time and probability of detection and signal to the fire brigade.

(b) Time and probability of brigade arrival at the building.

c) Time and probability of brigade set-up.

(d) Time and probability of brigade extinguishment.

The results developed from the Submodel are used directly in the Risk Assessment

Submodel. In the Risk Assessment Submodel it is assumed that provided the fire brigade arrive at an enclosure, and that the enclosure has not reached flashover, then the fire brigade have the capability to extinguish the fire.

The time for the fire brigade to commence extinguishment operations is defined as follows:

$\begin{aligned} & \text { Time to } \\ & \text { Commence } \\ & \text { Extinguishment }\end{aligned}=\begin{aligned} & \text { Time for } \\ & \text { Detection and } \\ & \text { Fire Brigade Signal }\end{aligned}+\begin{aligned} & \text { Time for } \\ & \text { Arrival }\end{aligned}+\begin{aligned} & \text { Time for } \\ & \text { Set-up }\end{aligned}$

The Time for Detection and Fire Brigade Signal is determined from the Fire Development Submodel. The Time for Arrival and Time for Set-up variables can be determined from fire brigade data. The probability components are currently determined on the basis of expert opinion. Further research is required to develop more comprehensive statistics on the fire brigade arrival and set-up times, and the probability of brigade performance, particularly concerning the probability of extinguishment. In addition, work is also required to quantify the risk-to-life safety for fire brigade personnel.

\section{Occupant Avoidance Submodel}

Occupant avoidance comprises a range of activities undertaken by occupants in attempting to avoid untenable conditions. The purpose of the occupant avoidance management subsystem is to facilitate, and enhance the action and ability of occupants in their attempts to avoid untenable conditions. The Occupant Avoidance Submodel is used to calculate the number of people exposed to untenable conditions.

The time available for occupant avoidance is defined as follows:

Duration Available for Occupant Avoidance

Time of Occurrence
of Untenable
Conditions

Time of Response of Occupants to a Cue

The Duration Available for Occupant Avoidance is defined for each combination of design fire, designated untenable condition, and particular cue condition (direct, indirect or automatic means). The Time of Occurrence of Untenable Conditions is determined using the Fire Development Submodel. The Time of Response of Occupants to a Cue is determined using the Occupant Communication and Response Submodel.

Once the Duration Available for Occupant Avoidance is known, it is then 
possible to use mathematical models to estimate the number of people exposed to untenable conditions. In the previous Risk Assessment Models, Beck [3] has described a model that was developed using performance results on human movement published by Pauls (for example refer Pauls [18]). A further mathematical model which could be used is the EVACNET model published by Kisko and Francis [19].

Both the Beck and EVACNET models determine occupant avoidance under so-called "normal" conditions; that is without the presence of fire. It is desirable that models be developed which readily (in terms of computer execution time) estimate the number of people exposed to untenable conditions based on considerations of particular fire scenarios (which may block particular egress routes in time), fire conditions which may hinder avoidance activities (for example, smoke obscuration), and occupant behavioural factors.

\section{OUTCOMES}

Results obtained from the application of risk assessment modelling to both office buildings (Beck and Poon [5]) and apartment buildings (Beck and Yung [8]) demonstrate that the inclusion of active subsystems, particularly occupant alarm and communication subsystems, have a beneficial effect on the expected risk-to-life performance parameter; the extent of the benefit is dependent upon the type of occupancy. Further, given moderate levels of fire-rated construction, then modest reductions in the level of fire-rated construction have little effect on the expected risk-to-life performance parameter but provide potentially significant reductions in the fire-cost expectation performance parameter.

The previously developed Risk Assessment Models for both office and apartment buildings give values for the ERL performance parameter which are significantly greater than comparable risk values based on a historical analysis of fire fatality records. This discrepancy is a reflection of both the assumptions invoked for the Risk Assessment Model and the limitations of the available data. In part reflection of this discrepancy, and in an attempt to ameloriate the effects of such discrepancies, it was decided to invoke a comparative decision-making criterion as described in the section entitled "Risk Assessment Modelling - Overview". This comparative (or code-equivalency) approach avoids the necessity of comparing the ERL value with independently defined absolute levels of risk which are deemed acceptable by the community.

However, in order to gain greater confidence in the use of risk assessment modelling as a tool for undertaking the identification of cost-effective fire safety system designs, it is necessary to improve the accuracy of the estimates for levels of risk-to-life safety. It is in part a response to the recognition of this need that the current research activities (as described in the previous section) are being undertaken. While research will result in improved accuracy of the estimates, there will always be some limitations attached to the results.

\section{CONCLUSIONS}

In Australia there have been considerable advances in recent years in the acceptance of the need for, and the development of, systematic cost-effective designs for fire safety systems in buildings. This has been achieved because there has been congruence of a unique set of circumstances. First, there has been a growing concern about both the conservative and restrictive nature of building regulations, and the need to reform the building regulations, based on rational engineering techniques. Second, research over ten years on risk assessment 
modelling has provided the basis for identifying cost-effective fire safety system designs. Third, three recent major initiatives, namely the Fire Safety and Engineering project conducted at the Warren Centre for Advanced Engineering, the development of the first draft of the National Building Fire Safety Systems Code, and the formation of the Australian Centre for Building Fire Safety and Risk Engineering, have resulted in both the acceptance and the further development of risk assessment modelling as the basis to identify cost-effective fire safety designs.

The use of mathematical models to calculate the expected effects of fire growth and spread in buildings necessarily involves the introduction of many assumptions, both of a conceptual and numerical nature. The risk assessment models described herein are classified as being intermediate between a simplistic model and an overly complex model. The risk assessment models have been developed cognisant of the data that is available or which could be readily obtained; statistical data is used where appropriate.

The previously developed risk assessment models have given estimates of risk-to-life safety which are significantly greater than equivalent risk values obtained from an analysis of historical records. To enable the reliable application of risk assessment modelling it is therefore necessary to further develop the existing risk assessment model and the complementary submodels. To facilitate this development it will be necessary to undertake a coordinated program of international research collaboration. This process has already commenced with the National Fire Laboratory, National Research Council of Canada.

The use of risk assessment models, RAMs, to assess cost-effective fire safety system designs is in an early stage of development. However, once improvements have been made to the RAMs, similar to those outlined in this paper, then it is considered appropriate that the results from such RAMs be used as a basis for deciding the most cost-effective fire safety system designs for buildings. The results from RAMs will permit more rational decisions to be made than is currently possible. It should be recognised also that once improvements (as outlined herein) have been made to the RAMs, opportunities will still remain to further improve the accuracy of the RAMs.

Risk assessment models can be used to:

(a) Identify alternative fire safety system design configurations which give equivalent performance to the existing code requirements (in terms of ERL values), but at a lower net cost (FCE value); that is, the alternative designs are more cost-effective.

(b) Provide a performance-based approach to design for fire which is applicable to both proposed building designs and also existing buildings.

(c) Appraise both existing building regulation (code) requirements and proposals to change code requirements, and investigate whether consistent cost-effective performance is provided by the various code requirements.

(d) Guide future research efforts into those areas which are identified as having a significant impact on the cost-effective provision of fire safety and protection.

\section{ACKNOWLEDGEMENT}

The Warren Centre "Fire Safety and Engineering" Project involved some 70 Project Fellows who were senior professionals from various disciplines and organisations associated with fire safety and protection in Australia. The significant contribution of the Project Fellows is gratefully acknowledged. The 
subsequent support of the Building Regulation Review Task Force for the first stage development of a National Building Fire Safety Systems Code is also gratefully acknowledged.

The development occurring in Australia could not have been achieved without the substantial involvement and support of the following personnel:

Dr. I. Thomas

Dr. C. Ramsay

Assoc. Prof. H. MacLennan

Mr. P. Johnson

Mr. R. Lacey

Mr. C. Eaton
BHP Research-Melbourne Laboratories

CSIRO Division of Building, Construction and

Engineering

University of Technology, Sydney

Scientific Services Laboratory, Australian

Construction Services

Lincolne Scott Aust., Consulting Engineers

Building Owners and Managers Association

This group (including the Victoria University of Technology) were the key members of the Warren Centre "Fire Safety and Engineering Project", they undertook the preparation of first draft of the National Building Fire Safety System Code, and they constitute the membership of the Australian Centre for Building Fire Safety and Risk Engineering.

The substantial contributions made by the Hazard Assessment Group, National Fire Laboratory, National Research Council of Canada, under the leadership of Dr. D. Yung, to the development of risk assessment models is gratefully acknowledged.

\section{REFERENCES}

1. Beck, V.R., "Outline of a Stochastic Decision-Making Model for Building Fire Safety and Protection", Fire Safety Journal, Vol. 6, No. 2, 1983, pp. 105-120.

2. Beck, V.R., "The Prediction of Probability of Failure of Structural Steel Elements Under Fire Conditions", Civil Engineering Transactions, The Institution of Engineers, Australia, Vol. CE27, No. 1, February, 1985, pp. 111-118.

3. Beck, V.R., "Cost-Effective Fire Safety and Protection Design Requirements for Buildings", PhD Thesis, University of New South Wales, July 1986.

4. Beck, V.R., "A Cost-Effective Decision-Making Model for Building Fire Safety and Protection", Fire Safety Journal, Vol. 12, 1987, pp. 121-138.

5. Beck, V.R., and Poon, S.L., "Results from a Cost-Effective Decision-Making Model for Building Fire Safery and Protection", Fire Safety Journal, Vol. 13, 1988, pp. 197-210.

6. Beck, V.R., and Yung D., "A Cost-Effective Risk-Assessment Model for Evaluating Fire Safety and Protection in Canadian Apartment Buildings", International Fire Protection Engineering Institute, Sth Conference, Ottawa, Ontario, Canada, 21-31 May 1989, Volume 1 Papers.

7. Yung, D., and Beck, V.R., "A Risk-Cost Assessment Model for Evaluating Fire Risks and Protection in Apartment Buildings", International Symposium on Fire Engineering for Building Structures and Safety, The Institution of Engineers, Australia, Melbourne, 14-15 November 1989, pp. 15-19. 
8. Beck, V.R., and Yung, D., "A Cost-Effective Risk-Assessment Model for Evaluating Fire Safety and Protection in Canadian Apartment Buildings", Journal of Fire Protection Engineering, Vol. 2, No. 3, 1990, pp. 65-74.

9. Warren Centre, "Project Report" and "Technical Papers, Books 1 and 2", Fire Safety and Engineering Project, The Warren Centre for Advanced Engineering, The University of Sydney, December 1989.

10. Quintiere, J.G., "Private Discussions", Warren Centre Project, May 1989.

11. Beck, V.R., "Fire Safety System Design - Developments in Australia", Conference on Fire Safety Design in the 21st Century, Society of Fire Protection Engineers, Worcester, Massachusetts, 8-10 May, 1991.

12. Quintiere, J.G., Birky, M., Macdonald, F., and Smith, G., "An Analysis of Smouldering Fires in Closed Compartments and their Hazard Due to Carbon Monoxide", Fire and Materials, Vol. 6, Nos. 3 and 4, 1982, pp. 99-110.

13. Jones, W.W., "A Model for the Transport of Fire, Smoke and Toxic Gases (FAST)", NIST, Center for Fire Research, NBSIR 85-3233, 1985.

14. Takeda, H., and Yung, D., "Simplified Fire Growth Models for Risk-Cost Assessments in Apartment Buildings", National Research Council of Canada, Ottawa, April 1991 (Submitted to the Journal of Fire Protection Engineering).

15. Roux, H.J., and Berlin, G.N., "Towards a Knowledge-Based Fire Safety System", in Smith, E.E., and Harmathy, T.Z., (Edts), "Design of Buildings for Fire Safety", ASTM STP 685, American Society for Testing and Materials, 1979, pp 3-13.

16. Hadjisophocleous, G., and Yung, D., "A Method of Calculating Probabilities of Smoke Hazard from Fires in Multi-Storey Buildings", National Research Council of Canada, Ottawa, April 1991 (Submitted to the Journal of Fire Protection Engineering).

17. Dusing, J.W.A., Buchanan, A.H., and Elms, D.G., "Fire Spread Analysis of Multi-Compartment Buildings", Research Report 79/12, Department of Civil Engineering, University of Canterbury, New Zealand, September 1979.

18. Pauls, J.L., "Building Evacuation: Research Findings and Recommendations", in Canter, D. (Editor), "Fires and Human Behaviour", John Wiley and Sons, Chichester, 1980.

19. Kisko, R.M. and Francis, R.L., "EVACNET: a Computer Program to Determine Optimal Building Evacuation Plans", Fire Safety Journal, Vol. 9, 1985, pp 211-220. 


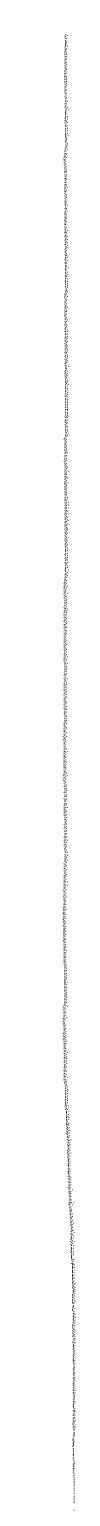

